\title{
Recognition - IJS Indexed in SCI expanded!
}

\author{
Satish Shukla
}

Nature is a beautiful creation of God in his own way, blossoms to give colour and fragrance, with wind blowing to enthril everyone and life gets its touch with happiness. Hundred and millions of years has laid the living creatures, developing into different forms and gradually humanity came into existence. Out of all creations/creatures, human life developed with the power of understanding, expression, analysis and reaction. Humans developed the present scenario gradually with two main feelings of competitiveness and recognition. Society is thus striving hard from the basic of survival of the fittest to survival to recognition and achieve the best. This holds good in all spheres including scientific developments. Medical science is progressing very fast and so also the development in the medical publication. Competitiveness has given quality publication and recognition by Scientist and Scientific Associations. Various agencies and houses have come together for this purpose and few are in demand to enhance its image and in turn better quality production.

Electronic media has grown many bounds in last decade and so is the case in scientific publication to cover wide areas and large target population. This has advanced knowledge efficiently in no time. Similarly monitoring and guiding facilities have come up to judge the publication and academic qualities of the journal. Institute of Scientific Information (ISI) currently known as Thomson scientific with the help of their librarians and information scientists have been evaluating journals for the past 75 years. The advent of the ISI citation indexes made it possible to do computer compiled statistical reports not only on the output of journals but also in term of citation frequency, made possible by advanced electronic information system. Thomson scientific analyses the datas and invented a system of impact factor of a journal and report is published in their Journal Citation Reports (JCR). Indian Journal of Surgery (IJS) is now a privileged journal indexed with the ISI and been cited in JCR. This is the first

S. Shukla $(\bowtie)$

Retired Professor \& HOD Surgery,

M.G.M. Medical College \& M.Y. \& Associated Hospital,

Indore, India

Director of Lakshmi Memorial Hospital \& Research Centre, Indore (M.P.), India

Editor/Chairman, Indian Journal of Surgery

E-mail: drsumit_shukla2003@yahoo.co.in big achievement of IJS in indexing process with international organisation beside more than 20 other indexing agencies. It has given an international recognition to IJS and ASI, and an international open field to our surgeons for their work to be RECOGNISED by universal scientific fraternity.

Why this indexing is important? Is it because we get wide open field to show our academic proficiency and untouched clinical material? Yes it is true but more so ISI, studies the journal, analyses its data inputs, calculates impact factor and guide regarding its true universal acceptability. The impact factor is directly proportional to number of citation of its author and articles. More the impact factor, more high is the journal grading and more number of scientists and institutions value the journal. It has its own commercial value also in terms of electronically accepted procedure of downloading the articles/journal.

This is the beginning of IJS recognition and all of us to work hard to grow better academically, maintain timely publication and emphasis on original and review articles. Many high profile institutions and associated scientist/ surgeons - known as hot spots and hot authors, in our country, do not subscribe to National Journals because of limited exposure to their achievements and their worldwide recognition. IJS and its board assures everyone to have a national outlook with international vision. IJS is a platform to project yourself. Why not be part of this great journal IJS and be proud of it. Your one contribution will take us way ahead of others and be proud of yourself.

Has IJS come up to your expectation? Your answer to this and your critical evaluation will help us in improving the journal. International faculties have approved of its quality and insist on maintaining it and suggests to improve further. You are the one to come forward with your vast academic resources around you, to give it a shape in terms of words and sentences to form an article. IJS will help you to write a good article. What is needed is your desire to write and recognise IJS as universally accepted journal.

Springer (India) and its present body Springer (International) of more than 150 years of publishing experience, have people of high knowledge in this field to guide us to take steps further to get RECOGNITION by other indexing agencies also. Right steps in right direction to boost our image are already taken. Time will give our efforts RECOGNITON we deserve. 